\title{
Preoperative Education for Hip and Knee Replacement: Never Stop Learning
}

\author{
Paul K. Edwards ${ }^{1} \cdot$ Simon C. Mears ${ }^{1}$ - C. Lowry Barnes ${ }^{1}$
}

Published online: 24 June 2017

(C) The Author(s) 2017. This article is an open access publication

\begin{abstract}
Purpose of review Participation in alternative payment models has focused efforts to improve outcomes and patient satisfaction while also lowering cost for elective hip and knee replacement. The purpose of this review is to determine if preoperative education classes for elective hip and knee replacement achieve these goals.

Recent findings Recent literature demonstrates that patients who attend education classes prior to surgery have decreased anxiety, better post-operative pain control, more realistic expectations of surgery, and a better understanding of their surgery. As a result, comprehensive clinical pathways incorporating a preoperative education program for elective hip and knee replacement lead to lower hospital length of stay, higher home discharge, lower readmission, and improved cost.

Summary In summary, we report convincing evidence that preoperative education classes are an essential element to successful participation in alternative payment models such as the Bundle Payment Care Initiative.
\end{abstract}

Keywords Alternative payment model $\cdot$ Hip replacement . Kneereplacement · Bundled payment · Discharge disposition · Hospital readmissions

This article is part of the Topical Collection on Quality and Cost Control in TJA

Paul K. Edwards

PKEdwards@uams.edu

1 Department of Orthopaedic Surgery, University of Arkansas for Medical Sciences, 4301 West Markham Street, Slot 531, Little Rock, AR 72205, USA

\section{Introduction}

Providing health care by alternative payment models (APM) is intended to improve the patient experience, improve the quality of health, and reduce the per capita cost of health care. Achieving this triple aim has become the core mission of the Institute for Healthcare Improvement (IHI). In 2013, the Center for Medicare and Medicaid Services (CMS) implemented the Bundled Payments for Care Improvement (BPCI) initiative in order to accomplish these goals. Increasing demands for hip and knee replacement in the aging population makes elective hip and knee replacement (DRG $470 \& 469)$ an ideal episode of care for participation in the BPCI.

Bundled payment models seek to align surgeons and hospitals by placing them at risk for financial penalty if adequate outcomes are not achieved or, oppositely, gain sharing opportunity if specified goals are reached. Successful participation depends on minimizing adverse events while simultaneously minimizing the associated costs. Regarding hip and knee replacement, hospital length of stay (LOS), discharge to postacute care (PAC) facilities, and hospital readmission are the primary drivers of cost during the episode of care [1-5].

Recent data supports the concept that cheaper care can be of higher quality. Shorter hospital LOS during the surgical admission as well as discharge to home rather than an extended nursing facility reduces readmissions and cost [2-6]. However, only recently has much been written regarding the actual steps to successfully accomplish these objectives $[7 \cdot, 8$, $9 \cdot, 10 \bullet, 11-13]$. Many of these recent reports have proposed that preoperative education plays a critical role to achieve these goals [7•, 14-24]. The aim of this paper is to focus on preoperative education and its role in elective hip and knee replacement. The purpose of this review is to provide compelling evidence supporting the use of preoperative education 
programs for elective hip and knee replacement to safely achieve the triple aims developed by the IHI.

\section{What Is Preoperative Education?}

Cochrane $\subseteq$ review defines preoperative education as any educational intervention delivered before surgery that aims to improve people's knowledge, health behaviors, and health outcomes. Interestingly, the 2014 Cochrane $\odot$ review concluded that preoperative education provided little benefit above standard patient care for hip or knee arthroplasty [25]. However, five of the nine studies used written, audiovisual, or a combination of these methods to educate the patient [14, $16,20,26]$. Most educators believe a vital component to the program includes a live class with in-person educators to teach the material and more importantly answer any remaining questions [16]. Since evidence has shown a patient's willingness to proceed with surgery may be influenced by how completely their questions are answered, the live class approach likely contributes to observed improvement in outcomes [27].

Changes in medical care with bundle payment models have also led to changes in patient education needs. Improving health before surgery as well as emphasizing the importance of family support and early discharge home have not been stressed in the past. The content of preoperative education varies, but typical education material contains information related to pre-surgical processes, the actual steps in the surgical procedure, discharge disposition, postoperative care, potential surgical and non-surgical complications, answers to frequently asked questions, postoperative pain management, and important contact numbers or emails. The format of education ranges from one-to-one verbal communication, patient group sessions, and video or booklet.

\section{Preoperative Education}

\section{Does It Work?}

Although not a new concept, there is a growing body of literature reporting improved outcomes when information and education regarding a patient's upcoming orthopedic surgery is provided in a timely manner [2-31]. Preoperative education classes have reported decreased pre- and post-operative anxiety, decreased post-operative pain, better coping, improved LOS, increased discharge to home, lower readmissions, and improved costs $[6,7 \cdot, 14-24,32]$. Preoperative programs have also been shown more beneficial than post-operative education programs [19].

Moulton et al. acknowledged that while numerous studies have demonstrated improvement in patient outcomes following the introduction of rapid recovery programs, the element of preoperative education remains controversial [24]. Yet, recent reports have shown that implementing clinical pathways (CP) with preoperative educational programs can successfully minimize LOS, decrease readmissions, and improve home discharge $[6,7 \cdot, 11-13]$. Although these comprehensive CP programs are multi-faceted, the educational component is most critical for success. Recent data showed that preoperative education as a single intervention decreased LOS following total knee arthroplasty with no increase in complications or readmissions within 90 days of discharge [33].

\section{Expectations}

Individuals undergoing joint replacement surgery have high expectations for their outcomes [34-38]. A strong correlation has been reported between patient satisfaction and fulfillment of pain relief and functional outcome [39]. For example, evidence shows that up to $20 \%$ of all total knee arthroplasty patients are not satisfied with their outcome and the strongest predictor was not meeting their expectations [34, 40, 41]. Preoperative education may improve patient expectations prior to surgery [38]. Patient expectations for pain relief and functional outcome have also been shown to be higher than their surgeons' expectations [42]. Aligning patient and surgeon expectations preoperative may lead to improved patient satisfaction after joint replacement. Education programs provide an opportunity to further define the surgeon and patient expectations before the elective surgery.

Preoperative education may also prepare patients psychologically for rehabilitation aims by providing them with clear expectations of the recovery process [43]. Providing the patient with adequate information may also increase their sense of responsibility for a successful surgery as well as improve the belief that they are able to cope with the surgery $[12,44]$.

\section{Anxiety}

Pain after total knee replacement correlates with increased preoperative anxiety levels [45]. Preoperative education may decrease patient anxiety related to an upcoming surgical procedure. Studies have reported that reducing preoperative anxiety in patients improves postoperative recovery, leads to higher levels of patient satisfaction with their surgical experience, and reduces levels of self-reported pain up to 1 year after surgery $[16,45,46]$. A recent non-experimental, descriptive study reported that $78 \%$ of participants believed that preoperative education reduced their anxiety prior to elective orthopedic surgery [47]. Several studies have evaluated the most effective means to improve patient anxiety prior to surgery and determined that providing information regarding the 
upcoming surgery and subsequent hospitalization is most beneficial [17, 18, 48-52] .

The continued existence of racial, ethnic, and gender disparities in total hip and knee replacement are well documented [53-56]. Several studies report that African-Americans had greater fear before and after joint replacement, had less knowledge than whites regarding joint replacement surgery, and were less likely to know someone that had undergone joint replacement [57-60]. For those patients undergoing hip and knee replacement, health beliefs including trust of healthcare providers are also critical issues for certain ethnic groups [59]. Studies also report women ask more questions related to their upcoming surgery and generally have higher anxiety levels regarding their surgery $[48,61]$. Preoperative education classes provide another opportunity to distribute additional educational information that may assuage some of the fears in those patients with higher anxiety.

\section{Health Literacy}

Health literacy as defined by the National Network of Libraries of Medicine is the degree to which individuals have the capacity to obtain, process, and understand basic health information and services needed to make appropriate health decisions [62]. Health literacy remains vital in achieving a patients' understanding of their upcoming surgery and is considered the single best predictor of an individual's health status [63-65]. However, only $12 \%$ of adults have proficient health literacy, according to the National Assessment of Adult Literacy [66]. Those patients with poor health literacy have decreased medical knowledge, poorer health-related outcomes, lower treatment satisfaction, increased hospitalizations, and worse communication with healthcare providers [63-65, 67-69]. For optimal comprehension and compliance, patient education material should be written at a sixth-grade or lower reading level, preferably including pictures and illustrations [70]. Yet, $81 \%$ of the patient education materials provided by the American Academy of Orthopaedic Surgeons (AAOS) had a readability score above the 8 th grade level, which is the mean adult reading level in the USA [71•, 72-75]. Other studies report similar readability of patient education materials across multiple surgical subspecialties including material provided by the American Society of Hand Surgery [76-78].

Providing education materials at the literacy level of our patients will improve their understanding of surgery, minimize anxiety, and improve outcomes that are clinically significant. Providing this material in plain language is vital to improving health literacy. Plain language is communication that users can understand the first time they read or hear it [79]. Patient education material can be more understandable by organizing information in order of importance, use active voice, shortening sentences, using simpler terms, avoiding medical jargon, and adding descriptive pictures [18, 79-81]. Additional formats such as YouTube videos tailored to a 6th grade level, may improve communication and further reduce preoperative anxiety $[82,83]$. Focusing efforts to improve the readability of all preoperative education print material will improve the health literacy of orthopedic patients undergoing elective hip and knee replacement.

\section{Social Support}

Previous studies have clearly demonstrated a strong link between patient outcomes and a patient's social support system. A patient's social support is associated with mortality, mental health, stress, and depression [84-87]. One study noted that perceived social support was an important factor after hip or knee replacement and that hospital nurses tended to determine the amount of social support by the number of visitors [88]. Preoperative education classes for elective total joint replacement have been shown to promote a sense of social connectedness while also fostering participants' independence [89]. A recent study by Mitchinson et al. concluded "limited social connectedness impacts negatively on the quality and rate of recovery after major operation, regardless of post-operative complications" [86]. In another study, patients reported that they were less anxious about their surgery as a result of attending preoperative classes, and the preoperative teaching by the multidisciplinary team was effective and highly valued [90]. The authors of this study concluded that a family member or caregiver ideally should be present with the patient during the preoperative education classes in order to better prepare for the upcoming surgery. Many other studies also consider the use of a family member/caregiver referred to as a "Coach" as a critical aspect to successful outcomes after surgery [7•, 8, 91-94]. In addition to requiring patients attend preoperative education class with a designated Coach, we have patients sign non-binding contracts clearly defining family members and friends in their social network that may be available to provide care during the acute surgical time period [8].

Patients with a strong social support have shorter hospital stays, are more likely to be discharged home, more likely to meet ambulation and transfer-out-of-bed targets, score hospital quality of care higher, and are more confident and ready to go home on discharge [91]. Three presence intervals were also found to be significant predictors of key outcome measures: family/friend presence during the preoperative classes, family/ friend presence in the preoperative holding area, and family/ friend presence during the last physical therapy session [91]. Importantly, education classes allow our healthcare team members to identify and educate these important crucial members of the patient's social network. Rarely, a patient has no social support. In these circumstances, the problem can be 
identified in class and the need for a coach can be stressed or discharge plans can be altered.

\section{Unforeseen Barriers to Home Discharge}

Unforeseen barriers to home discharge can delay discharge if not identified and addressed prior to surgery. In our experience, the education class often identifies recent changes in the patient's social family support system, an inability to obtain needed durable medical equipment, failed arrangements for transportation to outpatient physical therapy, unrealistic expectation of discharge to rehabilitation hospital, and/or other issues that may hinder timely discharge. Live education classes with in-person healthcare providers allow each of these concerns to be identified and addressed before surgery, and if not resolved, surgery is delayed until a solution is determined.

\section{Cost Savings}

In an effort to achieve the triple aims of the IHI, any opportunity to improve costs without sacrificing quality is beneficial. Preoperative education classes have shown a total cost savings averaging \$4016 (27.2\%) less than total costs for those patients who did not participate in preoperative education classes prior to elective hip or knee replacement [33]. While another study reported a cost savings of greater than $\$ 12,000$ per year in those patients who attended an education course prior to surgery [24].

\section{Adult Education Techniques}

Educating adult patients regarding surgical procedures can be accomplished by a variety of methods; in general, information tailored to the specific procedure in an interactive format provides the best results [95-97]. One key feature to improve learning and retention is through the use of repetition. Use of the spaced retention method increases memory retention up to $200 \%$ [98-100]. Spaced repetition is a learning technique that incorporates increasing intervals of time between subsequent reviews of previously learned material in order to exploit the psychological spacing effect [101]. Using the spaced retention method to repeat and reinforce patient expectations, goals, and the surgical information may be critical to improving outcomes. A comprehensive $\mathrm{CP}$ can provide spaced retention learning by aligning the surgeon, surgeon's mid-level provider, surgeon's office RN, Internal Medicine team, and the preoperative education instructors to teach correct detailed information in repetition at varying spaced intervals. We have accomplished this teaching method by reinforcing the goals and expectations for the patient's surgery at each interaction with a healthcare provider leading up to surgery day (Table 1).

\section{Interaction One}

Patient education almost always starts in the office with the surgeon providing one-to-one education at the time when the decision for surgery is confirmed. This education session informs the patient of the expectations, risks, and alternatives to the upcoming surgery. In general, since surgeons have higher expectations than their patients, this office visit provides a great opportunity to clearly define your expectations for them regarding discharge, disposition, pain control, and overall satisfaction [42]. Although this one-on-one education may be the most important in gaining your patients trust, often very little of the medical details are retained and patients often leave the medical office with many unanswered questions after this visit.

\section{Interaction Two}

Although not a separate visit, its importance cannot be understated. After the physician has discussed and answered questions regarding the risks, benefits, and alternatives of the surgery either a $\mathrm{RN}$ or mid-level provider sits with the patient to pick a surgery date, perform quick oral-dentition exam, and provide our hip and knee replacement print material. This is an

Table 1 Spaced retention method for preoperative education

\begin{tabular}{|c|c|c|c|}
\hline & Provider & Visit & Goals \\
\hline 1 & Surgeon-patient & Office & Discuss indications, expectations, goals, risks, and alternatives to surgery. \\
\hline 2 & $\mathrm{PA} / \mathrm{APN} / \mathrm{RN}-$ patient & Office after MD & $\begin{array}{l}\text { Reinforce the expectations and goals. Schedule surgery date. Give printed } \\
\text { paperwork and joint replacement educational material. }\end{array}$ \\
\hline 3 & $\mathrm{IM} / \mathrm{PCP}-$ patient & Office $<30$ days prior to surgery & $\begin{array}{l}\text { Reinforce the expectations and goals. Obtain preoperative labs and medically } \\
\text { optimize. }\end{array}$ \\
\hline 4 & $\begin{array}{l}\text { Preoperative education } \\
\text { class-patient and coach }\end{array}$ & $\begin{array}{l}\text { Office }<30 \text { days prior to surgery, } \\
\text { after IM/PCP visit }\end{array}$ & $\begin{array}{l}\text { Reinforce the expectations and goals. Live demonstration with visual aids. } \\
\text { Review printed educational material, tour facilities, arrange for any } \\
\text { outpatient PT or DME needs. Identify any outstanding issues that may } \\
\text { prevent home discharge. }\end{array}$ \\
\hline
\end{tabular}


opportune time to address any remaining questions, once again reinforcing our goals and expectations for their surgery.

\section{Interaction Three}

A primary care physician (PCP) or internal medicine (IM) physician optimizes all patients prior to surgery. Uniformity of preoperative clearance and any preoperative instruction is critical to provide efficient, consistent, cost-effective preoperative evaluation. We recommend standardizing the preoperative workup, as well as the pre- and postoperative instructions as much as possible. This can be accomplished by using a team of physicians familiar with the expectations and goals of your surgery. We have found it most beneficial to use either the hospital employed medicine group or our own orthopedic Sports Medicine/PCP physician to perform all of our preoperative clearance consults. This allows for uniform preoperative workup, as well as reinforcement of our expectations and goals for their upcoming surgery.

\section{Interaction Four}

The final interaction before surgery is the formal education class. It provides the best opportunity to discuss any remaining questions and recognize any unresolved concerns. The class is completed within 30 days of surgery and only after a PCP or IM physician has optimized or "cleared" the patient for surgery. A variety of teaching methods can be used for the education. In general, we use group sessions with live teaching from PowerPoint presentation and videos.

\section{Teaching Methods}

One-to-one teaching is appropriate when sensitive or private topics need to be discussed; however, this process is time consuming and not cost-effective for large groups of patients [102]. Most commonly with elective hip and knee replacement patients, group teaching is most applicable and has been shown very effective $[103,104]$. Other advantages to group teaching include the benefit of hearing answers to other questions from the other participants, group support, and modeling of behavior and skills by the group. Videotapes have been shown an effective way to educate as long as it delivers appropriate information in a short (less than $11 \mathrm{~min}$ ) time period $[105,106]$. Video education is even more effective when combined with live teaching from a healthcare provider [107]. Videotape and YouTube video teaching may be especially effective for low health literacy populations and those patients with high anxiety [82, 105, 108]. Fifty percent of patients responding to survey after attending a preoperative education prior to hip or knee replacement preferred verbal education, stating that this was clear and easy to understand [47]. While only $30 \%$ of respondents preferred videos or DVD's, $10 \%$ found viewing of $\mathrm{x}$-rays helpful and only $2 \%$ preferred written information [47].

\section{Education Class Structure}

Required attendance for the education class should be mandatory prior to elective hip or knee replacement surgery. Strict compliance is critical to eliminate any confusion among surgeons and staff. When patients request to skip class or fail to attend, we cancel surgery until education class has been completed. Using slight modifications to the preoperative education guidelines recommended by Spalding et al., we suggest the following [18]:

- Avoid medical jargon

- Presenters should be the treating staff

- Structure programs chronologically

- Demonstrations should provide visual images and models

- Education classes should be taught on or near the joint replacement floor

Our classes are taught at the hospital where surgery will occur on the joint replacement floor. Allowing patients to familiarize themselves with the parking garage, hospital grounds, and even viewing the private rooms in which they will stay reduces anxiety about their upcoming surgery. The orthopedic joint replacement team members, including but not limited to the Physician Assistant, Advanced Practice Nurse, Physical Therapists, and Registered Nurses teach the education class.

All live slideshows and print content are approved by the joint replacement surgeons performing elective hip and knee replacement. After surgeon approval, all education material should be reviewed and edited for readability. Since low health literacy is associated with a poorer ability to understand and follow health instructions, poorer health outcomes, and poorer use of health care services, the readability of all patient education material is provided at a 4th grade reading level [109].

Our class sessions are taught in groups allowing time for discussion and questions. Incorporating group sessions and spousal support into the education program may facilitate an improvement in outcomes [28, 110]. For these reasons, our own educational program requires a "coach" be present during the education classes. In addition to the educational component of the class, our instructors also identify the patient's social support system. We require patients to sign a nonbinding contract stating they have read and understand the goals of our clinical pathway [8]. More specifically, they understand our goal is for discharge home post-operative day 1 after elective joint replacement. We require our patients identify in writing their "coach," along with contact information for two additional family/friends that may be available on the day of discharge or in the immediate post-operative time period. 


\section{Results of Our Clinical Pathway}

Previously, we have shown that a well-coordinated CP with preoperative education as a key component can decrease LOS, minimize discharge to any facility other than home, lower readmission risk, and decrease cost $[7 \cdot, 32]$. More recently, we report a $14 \%$ reduction in costs per episode of joint replacement during participation in the CMS Bundled Payments for Care Improvement (BPCI) initiative [6]. In this study, we attribute the cost savings to maintaining a low LOS (2.13 days), high discharge to home rate ( $98.3 \%$ home), and low readmission rate. We believe we could not have achieved these results without a preoperative education class.

\section{Conclusion}

Compelling evidence demonstrates the success of preoperative education classes for elective hip and knee replacement in the new landscape of bundled payment models. Despite the findings of the Cochrane Review study, we believe the data presented in this review article combined with our own experiences and data demonstrates preoperative education classes prior to elective joint replacement is a key component to successful participation in APM systems.

\section{Compliance with Ethical Standards}

Conflict of Interest Paul K. Edwards and Simon C. Mears declare that they have no conflict of interest.

C. Lowry Barnes reports royalties from DJO, research support from ConforMIS and Corin, consultancy fees from Health Trust, royalties and consultancy fees from Medtronic and Zimmer, and consultancy fees from Responsive Risk Solutions, outside of the submitted work.

Human and Animal Rights and Informed Consent This article does not contain any studies with human or animal subjects performed by any of the authors.

Open Access This article is distributed under the terms of the Creative Commons Attribution 4.0 International License (http:// creativecommons.org/licenses/by/4.0/), which permits unrestricted use, distribution, and reproduction in any medium, provided you give appropriate credit to the original author(s) and the source, provide a link to the Creative Commons license, and indicate if changes were made.

\section{References}

Papers of particular interest, published recently, have been highlighted as:

- Of importance

1. Dobson A, DaVanzo J, Heath S, et al. Medicare Payment Bundling: Insights from Claims Data and Policy Implications: Analyses of Episode-based Payment. Located at: American Hospital Association and Association of American Medical Colleges; 2012.
2. Mabrey JD, Toohey JS, Armstrong DA, et al. Clinical pathway management of total knee arthroplasty. Clin Orthop Relat Res. 1997;345:125.

3. Bini SA, Fithian DC, Paxton LW, et al. Does discharge disposition after primary total joint arthroplasty affect readmission rates? J Arthroplast. 2010;25(1):114.

4. Ramos NL, Karia RJ, Hutzler LH, et al. The effect of discharge disposition on 30-day re- admission rates after total joint arthroplasty. J Arthroplast. 2014;29(4):674.

5. Miller DC, Gust C, Dimick JB, et al. Large variations in Medicare payments for surgery highlight savings potential from bundled payment programs. Health Aff (Millwood). 2011;30(11):2107.

6. Edwards PK, Mears SC, Barnes CL. BPCI: Everyone Wins, Including the Patient. Journal of Arthroplasty. In Press Accepted Manuscript. Published online: February 28, 2017 doi:10.1016/j. arth.2017.02.014.

7. Edwards PK, Levine M, Cullinan K, Newbern G, Barnes CL. Avoiding readmissions-support systems required after discharge to continue rapid recovery? J Arthroplasty. 2015;30(4):527-30. doi:10.1016/j.arth.2014.12.029. Incorporating a patient management support system with preoperative education into our clinical pathway significantly reduced readmissions from $205(16.0 \%)$ to $54(9.2 \%)$ while maintaining a low length of stay (1.2 days).

8. Edwards PK, Barnes CL. Dealing with the outliers-Physicians, inpatient post-acute care providers, physical therapists, and visiting nursing facilities. Seminars in Arthroplasty. (2016); 27(3) .

9. Althausen PL, Mead L. Bundled Payments for Care Improvement: Lessons Learned in the First Year. J Orthop Trauma. 2016;30(Suppl 5):S50-3. doi:10.1097/BOT.0000000000000715. Reports on the lessons learned from participation in bundled payments for total joint arthroplasty episodes of care as well as the hip and femur fracture episode of care. The first year experience demonstrated that a significant learning curve is required. Keys for success include appropriate patient selection for elective surgery, implant pricing control, adherence to preoperative and postoperative protocols, diligent postcare care management, and appropriate choice of metrics to maximize gainsharing potential.

10. Iorio R, Bosco J, Slover J, Sayeed Y, Zuckerman JD. Single Institution Early Experience with the Bundled Payments for Care Improvement Initiative. J Bone Joint Surg Am. 2017;99(1): e2. doi:10.2106/JBJS.16.00066. Early reports from participation in the total joint arthroplasty BPCI experience at our tertiary-care academic medical center reveal a substantial investment in infrastructure is required to develop programs to improve coordination of care, manage quality data, and distribute payments. Smaller institutions may have difficulty devoting resources to these infrastructural changes, although changes may be implemented more thoroughly once initiated.

11. Berend KR, Lombardi AV, Mallory TH. Rapid recovery protocol for peri-operative care of total hip and total knee arthroplasty patients. Surg Technol Int. 2004;13:239-47.

12. MacDonald V, Arthur B, Parent S. The Vancouver general hospital joint replace- ment rapid recovery program: optimizing outcomes through focused pathways. J Orthop Nurs. 2005;9:95-102.

13. Pennington JM, Jones DPG, McIntyre S. Clinical pathways in total knee arthroplasty. A New Zealand experience. J Orthop Surg. 2003;11:165-73.

14. Crowe J, Henderson J. Pre-arthroplasty rehabilitation is effective in reducing hospital stay. Can J Occup Ther. 2003;70:88-96.

15. Kelly MH, Ackerman M. Total joint arthroplasty: a comparison of past acute settings on patient functional outcomes. Orthop Nurs. 1999;18:75-84. 
16. Daltroy LH, Morlino CI, Eaton HM, Poss R, Liang MH. Preoperative education for total hip and knee replacement patients. Arthritis Care Res. 1998;11:469-78.

17. Sjoling M, Nordahl G, Olofsson N, Asplund K. The impact of preoperative information on state anxiety, postoperative pain and satis- faction with pain management. Patient Educ Couns. 2003;51:169-76. doi:10.1016/S0738-3991(02)00191-X.

18. Spalding NJ. Reducing anxiety by pre-operative education: make the future familiar. Occup Ther Int. 2003;10:278-93. doi:10.1002/ oti.191.

19. Lin PC, Lin LC, Lin JJ. Comparing the effectiveness of different edu- cational programs for patients with total knee arthroplasty. Orthop Nurs. 1997;16:43-9. doi:10.1097/00006416-19970900000013.

20. Butler GS, Hurley CA, Buchanan KL, Smith-VanHorne J. Prehospital education: effectiveness with total hip replacement surgery patients. Patient Educ Couns. 1996;29:189-97. doi:10.1016/ 0738- 3991(96)00883-X.

21. Bondy LR, Sims N, Schroeder DR, Offord KP, Narr BJ. The effect of anesthetic patient education on preoperative patient anxiety. Region Anesth Pain Med. 1999;24:158-64. doi:10.1097/ 00115550-199924020- 00011.

22. Giraudet-Le Quintrec JS, Coste J, Vastel L, Pacault V, Jeanne L, Lamas JP, et al. Positive effect of patient education for hip surgery: a randomized trial. Clin Orthop Relat R. 2003;1:112-20.

23. Gammon J, Mulholland CW. Effect of preparatory information prior to elective total hip replacement on post-operative physical coping outcomes. Int J Nurs Stud. 1996;33:589-604. doi:10.1016/ S0020- 7489(96)00019-3.

24. Moulton LS. Evans, P. A., starks, I. And Smith, T. Pre-operative education prior to elective hip arthroplasty surgery improves postoperative outcome. Int Orthop. 2015;39(8):1483-6.

25. McDonald S, Page MJ, Beringer K, Wasiak J, Sprowson A. Preoperative education for hip or knee replacement. Cochrane Database Syst Rev. 2014;13(5):CD003526. doi:10.1002/ 14651858.CD003526.pub3.

26. Clode-Baker E, Draper E, Raymond N, Haslam C, Gregg P. Preparing patients for total hip replacement: a randomized controlled trial of preoperative education intervention. J Health Psychol. 1997;2:107-14.

27. Suarez-Almazor ME, Richardson M, Kroll TL, Sharf BF. A qualitative analysis of decision-making for total knee replacement in patients with osteoarthritis. J Clin Rheumatol. 2010 Jun;16(4): 158-63. doi:10.1097/RHU.0b013e3181df4de4.

28. Claeys M, Mosher C, Reesman D. The POP program: the patient education advantage. Orthop Nurs. 1998 Jul-Aug;17(4):37-47.

29. Dorr LD, Chao L. The emotional state of the patient after total hip and knee arthroplasty. Clin Orthop Relat Res. 2007 Oct;463:7-12.

30. Suhonen R, Leino-Kilpi H. Adult surgical patients and the information provided to them by nurses: a literature review. Patient Educ Couns. 2006 Apr;61(1):5-15.

31. Pownall E. Using a patient narrative to influence orthopaedic nursing care in fractured hips. J Orthop Nurs. 2004 Aug;8(3):151-9.

32. Tait MA, Dredge C, Barnes CL. Preoperative patient education for hip and knee arthroplasty: financial benefit? J Surg Orthop Adv. 2015 Winter;24(4):246-51.

33. Jones S, Alnaib M, Kokkinakis M, Wilkinson M, St Clair Gibson A, Kader D. Pre-operative patient education reduces length of stay after knee joint arthroplasty. Ann R Coll Surg Engl. 2011;93:71-5. doi:10.1308/003588410X12771863936765.

34. Bourne RB, Chesworth BM, Davis AM, Mahomed NN, Charron KD. Patient satisfaction after total knee arthroplasty: who is satisfied and who is not? Clin Orthop Relat Res. 2010;468:57-63.

35. Iversen MD, Daltroy LH, Fossel AH, Katz JN. The prognostic importance of patient pre-operative expectations of surgery for lumbar spinal stenosis. Patient Educ Couns. 1998;34:169-78.
36. Lingard EA, Sledge CB, Learmonth ID. Patient expectations regarding total knee arthroplasty: differences among the United States, United Kingdom, and Australia. J Bone Joint Surg Am. 2006;88:1201-7.

37. Mahomed NN, Liang MH, Cook EF, Daltroy LH, Fortin PR, Fossel $\mathrm{AH}$, et al. The importance of patient expectations in predicting functional outcomes after total joint arthroplasty. J Rheumatol. 2002;29:1273-9.

38. Mancuso CA, Graziano S, Briskie LM, Peterson MG, Pellicci PM, Salvati EA, et al. Randomized trials to modify patients' preoperative expectations of hip and knee arthroplasties. Clin Orthop Relat Res. 2008;466:424-31.

39. Scott CE, Bugler KE, Clement ND, MacDonald D, Howie CR, Biant LC. Patient expectations of arthroplasty of the hip and knee. J Bone Joint Surg Br. 2012;94:974-81.

40. Nilsdotter AK, Toksvig-Larsen S, Roos EM. Knee arthroplasty: are patients' expectations fulfilled? A prospective study of pain and function in 102 patients with 5-year follow-up. Acta Orthop. 2009 Feb;80(1):55-61. doi:10.1080/ 17453670902805007.

41. Ronnberg K, Lind B, Zoega B, Halldin K, Gellerstedt M, Brisby H. Patients' satisfaction with provided care/information and expectations on clinical outcome after lumbar disc herniation surgery. Spine. 2007;32(2):256-61.

42. Ghomrawi HM, Franco Ferrando N, Mandl LA, Do H, Noor N, Gonzalez Della Valle A. How often are patient and surgeon recovery expectations for Total joint arthroplasty aligned? Results of a pilot study. HSSJ. 2011;7:229-34. doi:10.1007/s11420-011-92036.

43. Loft M, McWilliam C, Ward-Griffin C. Patient empowerment after total hip and knee replacement. Orthop Nurs. 2003;22:42-7.

44. Lucas B. Preparing patients for hip and knee surgery. Nurs Stand. 2007;22:50-8.

45. Brander Victoria A, Stulberg S David, Adams Angela D, Harden R Norman, Bruehl Stephen, Stanos Steven P, Houle Timothy. Predicting total knee replacement pain: a prospective, observational study. Clin Orthop Relat Res. 2003 (416):27-36. Doi: 10.1097/ 01.blo.0000092983.12414.e9.

46. Riddle Daniel L, Wade James B, Jiranek William A. Kong Xiangrong. Preoperative pain catastrophizing predicts pain outcome after knee arthroplasty. Clin Orthop Relat Res. 2010 Mar;468(3):798-806. doi:10.1007/s11999-009-0963-y.

47. Chetty C, Ehlers VJ. Orthopaedic patients' perceptions about their pre-operative information. Curationis. 2009;32(4):55-60.

48. Miller SM, Mangan CE. Interacting effects of information and coping style in adapting to gynecologic stress: should the doctor tell all? J Pers Soc Psychol. 1983 Jul;45(1):223-36.

49. Brander V, Gondek S, Martin E, Stulberg SD. THE JOHN INSALL AWARD: Pain and depression influence outcome 5 years after knee replacement surgery. Clin Orthop Relat Res. 2007 Nov;464:21-6. doi:10.1097/BLO.0b013e318126c032.

50. Carlo R, Elisabetta V, Giovanni R. Effectiveness of an informative video on reducing anxiety levels in patients undergoing elective coronarography: an RCT. Eur J Cardiovasc Nurs. 2009 Mar;8(1): 57-61. doi:10.1016/j.ejcnurse.2008.04.002.

51. Jlala HA, French JL, Foxall GL, Hardman JG, Bedforth NM. Effect of preoperative multimedia information on perioperative anxiety in patients undergoing procedures under regional anaesthesia. Br J Anaesth. 2010 Mar;104(3):369-74. doi:10.1093/bja/ aeq002.

52. Johnston M, Vögele C. Benefits of psychological preparation for surgery: a meta-analysis. Ann Behavior Med. 1993;15(4):245-56.

53. Jha AK, et al. Racial trends in the use of major procedures among the elderly. N Engl J Med. 2005;353(7):683-91.

54. Hanchate Amresh D. Zhang Yuqing, Felson David T, ash Arlene S. Exploring the determinants of racial and ethnic disparities in total knee arthroplasty: health insurance, income, and assets. Med 
Care. 2008 May;46(5):481-8. doi:10.1097/MLR. 0b013e3181621e9c.

55. Skinner J, Zhou W, Weinstein J. The influence of income and race on total knee arthroplasty in the United States. J Bone Joint Surg Am. 2006 Oct;88(10):2159-66. doi:10.2106/JBJS.E.00271.

56. Hawker GA, Wright JG, Coyte PC, Williams JI, Harvey B, Glazier R, et al. Differences between men and women in the rate of use of hip and knee arthroplasty. N Engl J Med. 2000 Apr 6;342(14):1016-22. doi:10.1056/NEJM200004063421405.

57. Suarez-Almazor ME, et al. Ethnic variation in knee replacement: patient preferences or uninformed disparity? Arch Intern Med. 2005;165(10):1117-24.

58. Chang HJ, et al. Concerns of patients actively contemplating total knee replacement: differences by race and gender. Arthritis Rheum. 2004;51(1):117-23.

59. Lavernia CJ, Alcerro JC, Rossi MD. Fear in arthroplasty surgery: the role of race. Clin Orthop Relat Res. 2010;468(2):547-54. doi: 10.1007/s11999-009-1101-6.

60. Blake VA, et al. Racial differences in social network experience and perceptions of bene $t$ of arthritis treatments among new York City Medicare beneficiaries with self- reported hip and knee pain. Arthritis Rheum. 2002;47(4):366-71. doi:10.1002/art.10538.

61. Maria M, Shell Jasmine E, Thomas Colleen S, Ortiguera Cedric J, O'Connor Mary I. Gender differences in questions asked in an online preoperative patient education program. Gend Med. 2012 Dec;9(6):457-62. doi:10.1016/j.genm.2012.10.002.

62. https://nnlm.gov/professional-development/topics/health-literacy.

63. Baker DW, Parker RM, Williams MV, Clark WS, Nurss J. The relationship of patient reading ability to self-reported health and use of health services. Am J Public Health. 1997;87:1027-30.

64. Johnson K, Weiss BD. How long does it take to assess literacy skills in clinical practice? J Am Board Fam Med. 2008;21:211-4.

65. Weiss BD. Health literacy: a manual for clinicians. American Medical Association, American Medical Foundation: Chicago, IL; 2003.

66. Kirsch IS, Jungeblut A, Jenkins L, Kolstad A. Adult literacy in America: a first look at the results of the National Adult Literacy Survey (NALS). Washington, DC: National Center for Education Statistics, U.S. Department of Education; 1993.

67. Pendlimari R, Holubar SD, Hassinger JP, Cima RR. Assessment of colon cancer literacy in screening colonoscopy patients: a validation study. J Surg Res. 2012;175:221-6.

68. Basarudeen S, Sabharwal S. Assessing readability of patient education materials: current role in orthopaedics. Clin Orthop Relat Res. 2010;468:2572-80.

69. Roh YH, Lee BK, Park MH, Noh JH, Gong HS, Baek GH. Effects of health literacy on treatment outcome and satisfaction in patients with mallet finger injury. J Hand Ther. 2016;29(4):459-64. doi:10. 1016/j.jht.2016.06.004.

70. Safeer RS, Keenan J. Health Literacy: The Gap Between Physicians and Patients. Am Fam Physician. 2005;72(3):463-8.

71. Eltorai AE, Sharma P, Wang J, Daniels AH. Most American Academy of Orthopaedic Surgeons' online patient education material exceeds average patient reading level. Clin Orthop Relat Res. 2015;473(4):1181-6. doi:10.1007/s11999-014-4071-2. Most of the online patient education materials from the AAOS had readability levels that are far too advanced for many patients to comprehend. Efforts to adjust the readability of online education materials to the needs of the audience may improve the health literacy of orthopaedic patients. Patient education materials can be made more comprehensible through use of simpler terms, shorter sentences, and the addition of pictures.

72. Doak CC, Doak LG, Root JH. Teaching patients with low literacy skills. 2. JB Lippincott: Philadelphia; 1996.
73. Doak CC, Doak LG, Friedell GH, Meade CD. Improving comprehension for cancer patients with low literacy skills: strategies for clinicians. CA Cancer J Clin. 1998;48:151-62. doi:10.3322/ canjclin.48.3.151.

74. Organization for Economic Co-operation and Development. Time for the US to Reskill? What the Survey of Adult Skills Says: OECD Skills Studies. East Jerusalem: OECD Publishing; 2013.

75. US Department of Education, National Center for Education Statistics. The NAEP Reading Achievement Levels by Grade. Washington, DC: US Department of Education; 2011.

76. Hansberry DR, Agarwal N, Shah R, Schmitt PJ, Baredes S, Setzen $\mathrm{M}$, et al. Analysis of the readability of patient education materials from surgical subspecialties. Laryngoscope. 2014 Feb;124(2): 405-12. doi:10.1002/lary.24261.

77. Rosenbaum AJ, Pauze D, Pauze D, Robak N, Zade R, Mulligan $\mathrm{M}$, et al. Health literacy in patients seeking Orthopaedic care: results of the literacy in musculoskeletal problems (LIMP) project. Iowa Orthop J. 2015;35:187-92.

78. Hadden K, Prince LY, Schnaekel A, Couch CG, Stephenson JM, Wyrick TO. Readability of patient education materials in Hand surgery and health literacy best practices for improvement. J Hand Surg Am. 2016 Aug;41(8):825-32. doi:10.1016/j.jhsa. 2016.05.006.

79. Plain Language Action and Information Network. What Is Plain Language? www.plainlanguage.gov. Accessed on October 21, 2005.

80. Albright J, de Guzman C, Acebo P, Paiva D, Faulkner M, Swanson J. Readability of patient education materials: implications for clinical practice. Appl Nurs Res. 1996;9:139-43. doi: 10.1016/S0897-1897(96)80254-0.

81. Cotugna N, Vickery CE, Carpenter-Haefele KM. Evaluation of literacy level of patient education pages in health-related journals. J Community Health. 2005;30:213-9. doi:10.1007/s10900-0041959-x.

82. O’Connor MI, Brennan K, Kazmerchak S, Pratt J. YouTube videos to create a "virtual hospital experience" for hip and knee replacement patients to decrease preoperative anxiety: a randomized trial. Interact J Med Res. 2016;5(2):e10. doi:10.2196/ijmr. 4295.

83. Hamzah HS, Gao X, Yung Yiu CK, McGrath C, King NM. Managing dental fear and anxiety in pediatric patients: a qualitative study from the public's perspective. Pediatr Dent. 2014;36(1): 29-33.

84. Schoenbach VJ, Kaplan BH, Fredman L, Kleinbaum DG. Social ties and mortality in Evans County. Georgia Am J Epidemiol. 1986;123(4):577-91.

85. Seeman TE. Social ties and health: the benefits of social integration. Ann Epidemiol. 1996;6(5):442-51.

86. Mitchinson AR, Kim HM, Geisser M, Rosenberg JM, Hinshaw DB. Social connectedness and patient recovery after major operations. J Am Coll Surg. 2008;206(2):292-300.

87. George LK, Blazer DG, Hughes DC, Fowler N. Social support and the outcome of major depression. Br J Psychiatry. 1989;154: 478-85.

88. van den Akker-Scheek I, Stevens M, Spriensma A, van Horn JR. Groningen Orthopaedic social support scale: validity and reliability. J Adv Nurs. 2004;47(1):57-63.

89. Lane-Carlson ML, Kumar J. Engaging patients in managing their health care: patient perceptions of the effect of a total joint replacement presurgical class. Perm J. 2012;16(3):42-7.

90. Prouty A, Cooper M, Thomas P, Christensen J, Strong C, Bowie $\mathrm{L}$, et al. Multidisciplinary patient education for joint replacement surgery patients. Orthop Nurs. 2006;25:257-61.

91. Theiss MM, Ellison MW, Tea CG, Warner JF, Silver RM, Murphy VJ. The connection between strong social support and joint 
replacement outcomes. Orthopedics. 2011;34(5):357. doi:10. 3928/01477447-20110317-02.

92. Jester R. Early discharge to hospital at home: should it be a matter of choice? J Orthop Nurs. 2003;7:64-9.

93. Johansson K, Hupli M, Salanterä S. Patients' learning needs after hip arthoplasty. J Clin Nurs. 2002;11:634-9.

94. Ottenbacher KJ, Smith PM, Illig SB, Fiedler RC, Gonzales VA, Granger CV. Prediction of follow-up living settings in patients with lower limb joint replacement. Am J Phys Med Rehabil. 2002;81:471-7.

95. Luck A, Pearson S, Maddern G, Hewett P. Effects of video information on precolonoscopy anxiety and knowledge: a randomised trial. Lancet. 1999;354(9195):2032-5.

96. Nyman Samuel R. Yardley Lucy. Usability and acceptability of a website that provides tailored advice on falls prevention activities for older people. Health Informatics J. 2009;15(1):27-39. doi:10. 1177/1460458208099866.

97. Herrmann KS, Kreuzer H. A randomized prospective study on anxiety reduction by preparatory disclosure with and without video film show about a planned heart catheterization. Eur Heart J. 1989;10(8):753-7.

98. Spitzer HF. Studies in retention. J Educ Psychol. 1939;30:641-57.

99. Melton AW. The situation with respect to the spacing of repetitions and memory. J Verbal Learn Verbal Behav. 1970;9:596-606.

100. Landauer TK, Bjork RA. Optimum rehearsal patterns and name learning. In: Gruneberg M, Morris PE, Sykes RN, editors. Practical aspects of memory. London: Academic Press; 1978. p. 625-32.
101. Baddeley AD. Human memory: theory and practice, 1997.

102. Redman BK. The practice of patient education. Inc, St. Louis: Mosby Year Book; 1997.

103. Freda MC, Damus K, Merkatz IR. What do pregnant women know about the prevention of preterm birth? J Obstet Gynecol Neonatal Nurse. 1991;20:140-5.

104. Freda MC, Damus K, Andersen HF, Merkatz IR. A PROPP for the Bronx: preterm birth prevention education in the inner city. Obstet Gynecol. 1990;76:93-6.

105. Freda MC, Abruzzo M, Davini D, DeVore N, Damus K, Merkatz IR. Are they watching? Are they learning? Prenatal video education in the waiting room. J Perinat Ed. 1994;3:20-8.

106. O’Donnell L, San Doval A, Vornfett R, DeJong W. Reducing AIDS and other STDs among inner city Hispanics: the use of qualitative research in the development of video-based patient education. AIDS Educ Prev. 1994;6:140-53.

107. O’Donnell LN, San Doval AS, Duran R, O'Donnell C. Videobased sexually transmitted disease patient education: its impact on condom acquisition. Am J Public Health. 1995;85:817-22.

108. Williams NH, Wolgin F, Hodge CS. Creating an educational videotape. J Nurs Staff Dev. 1998;14:261-5.

109. Shnaekel A, Hadden K, Barnes CL. Readability of online patient educational materials on pain management. J Surg Orthop Adv. 2015 Winter;24(4):242-5.

110. Showalter A, Burger S, Salyer J. Patients' and their spouses' needs after total joint arthroplasty: a pilot study. Orthop Nurs. 2000;19: $49-57$. 